\title{
Partition of spaces based algorithm for reduction of real power loss
}

\author{
Kanagasabai Lenin \\ Department of Electrical and Electronics Engineering, Prasad V. Potluri Siddhartha Institute of Technology, India
}

\begin{tabular}{l} 
Article Info \\
\hline Article history: \\
Received Jan 10, 2018 \\
Revised Feb 16, 2018 \\
Accepted Feb 19, 2020 \\
\hline
\end{tabular}

Keywords:

Algorithm

Optimal reactive power

transmission loss

Partition of spaces

\begin{abstract}
In this work partition of spaces algorithm is proposed to solve optimal reactive power problem. In this algorithm, for finding the finest outcome based on the concentration of elevated quality and capable points in specific area is considered. State space area are identified and divided into subspaces iteratively and search has been made more comprehensively. Performance of the proposed partition of spaces algorithm is evaluated in standard IEEE 118,300 bus systems and simulated outcome gives better results. Real power loss has been considerably reduced.
\end{abstract}

Corresponding Author:

Kanagasabai Lenin,

Department of Electrical and Electronics Engineering,

Prasad V. Potluri Siddhartha Institute of Technology,

Kanuru, Vijayawada, Andhra Pradesh -520007, India.

Email: gklenin@gmail.com

\section{INTRODUCTION}

Optimal reactive power problem has been key problem in power system, since it plays major role in secure and economic operation of the power system. Many conventional methods [1-6] have been applied for solving optimal reactive power problem. But many drawbacks have been found in the conventional methods and mainly difficulty in handling the inequality constraints. Last two decades many evolutionary algorithms [7-18] continuously applied to solve the problem. In this paper, partition of spaces algorithm is proposed to solve the reactive power problem. In this approach, elevated quality and capable points of the area is taken. State space are identified and divided into subspaces iteratively and search has been made more comprehensively. Performance of the proposed algorithm is evaluated in standard IEEE 118,300 bus systems simulation results shows the better performance of the proposed algorithm in reduction of real power loss.

\section{PROBLEM FORMULATION} and given,

The key objective of the reactive power problem is to minimize the system real power loss

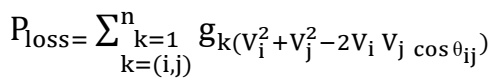

Voltage deviation magnitudes (VD) is stated as follows: 
Minimize $\mathrm{VD}=\sum_{\mathrm{k}=1}^{\mathrm{nl}}\left|\mathrm{V}_{\mathrm{k}}-1.0\right|$

Load flow equality constraints:

$$
\begin{aligned}
& P_{G i}-P_{D i}-V_{i \sum_{j=1}^{n b} V_{j}}\left[\begin{array}{cc}
G_{i j} & \cos \theta_{i j} \\
+B_{i j} & \sin \theta_{i j}
\end{array}\right]=0, i=1,2 \ldots, n b \\
& Q_{G i}-Q_{D i}-V_{i \sum_{j=1}^{n b} v_{j}}\left[\begin{array}{cc}
G_{i j} & \sin \theta_{i j} \\
+B_{i j} & \cos \theta_{i j}
\end{array}\right]=0, i=1,2 \ldots, n b
\end{aligned}
$$

Inequality constraints are:

$$
\begin{aligned}
& V_{\mathrm{Gi}}^{\min } \leq \mathrm{V}_{\mathrm{Gi}} \leq \mathrm{V}_{\mathrm{Gi}}^{\mathrm{max}}, \mathrm{i} \in \mathrm{ng} \\
& \mathrm{V}_{\mathrm{Li}}^{\mathrm{min}} \leq \mathrm{V}_{\mathrm{Li}} \leq \mathrm{V}_{\mathrm{Li}}^{\mathrm{max}}, \mathrm{i} \in \mathrm{nl} \\
& \mathrm{Q}_{\mathrm{Ci}}^{\min } \leq \mathrm{Q}_{\mathrm{Ci}} \leq \mathrm{Q}_{\mathrm{Ci}}^{\max }, \mathrm{i} \in \mathrm{nc} \\
& \mathrm{Q}_{\mathrm{Gi}}^{\min } \leq \mathrm{Q}_{\mathrm{Gi}} \leq \mathrm{Q}_{\mathrm{Gi}}^{\max }, \mathrm{i} \in \mathrm{ng} \\
& \mathrm{T}_{\mathrm{i}}^{\min } \leq \mathrm{T}_{\mathrm{i}} \leq \mathrm{T}_{\mathrm{i}}^{\max }, \mathrm{i} \in \mathrm{nt} \\
& \mathrm{S}_{\mathrm{Li}}^{\min } \leq \mathrm{S}_{\mathrm{Li}}^{\max }, \mathrm{i} \in \mathrm{nl}
\end{aligned}
$$

\section{PARTITION OF SPACES ALGORITHM}

In this algorithm, for finding the optimal solution based on the concentration of elevated quality and capable points in specific area is considered. With equal sizes the state space are alienated into some subspaces. In the state space uniformly, points are generated arbitrary mode and target function value is calculated. Promising points are chosen with each subspace is determined. Always the chances of finding the optimal solution are higher when promising points are considered as the promising subspaces. The details of the proposed algorithm are as follows:

a. Initially whole state space is measured as the capable area.

b. Subspaces are created from the state space. Until finally a grid containing $\mathrm{gi}_{1} \times \mathrm{gi}_{2} \times \ldots \mathrm{gi}_{\mathrm{n}}$ subsections in $\mathrm{d}^{\text {th }}$ dimension $(1 \leq \mathrm{d} \leq \mathrm{n})$ and is divided into as many as $\mathrm{g}_{\mathrm{d}}$ equivalent subintervals. Then, Size of each subinterval,

$$
\text { in dth dimension }=\frac{U_{d}-L_{d}}{g i_{d}}
$$

c. Preliminary population are created arbitrarily and that population is considered as the existing population.

d. For every point of the existing population of function " $\mathrm{f}$ " is computed.

e. Q1 - \% of points; existing population are regarded as capable points, with the lowest values of function $\mathrm{f}$,

f. In each of the subspaces the numbers of capable points are determined and indicate the degree of capable points in the subspace.

Capable ranks $=$ Number of capable points in "s"

g. Q2 subspaces are searched more accurately and comprehensively.

1) Extra specific search in the capable subspaces: smaller subspaces are made from the capable subspaces.

2) To search subspaces expansively the number of points generated in each subspace is a linear function and found by [19]:

number os points generated in $\mathrm{s}=\left(\frac{\text { capable rank }_{\mathrm{s}}}{\sum_{\mathrm{k} \in \text { all sub spaces }}{\text { capable rank } \mathrm{k}_{\mathrm{k}} \times \text { population size }}}\right)$ 
h. For each point in the new population the value of function $\mathrm{f}$ is calculated.

i. Based on the truncation selection new population are replace the current population.

j. Q3 percent of the points are arbitrarily selected in new population and customized by adding a Gaussian noise to them it's alike to mutation operation in genetic algorithm.

k. Evaluation of the stop condition.

1. The output of algorithm is the most excellent solution generated so far. Trade-off between exploration and exploitation is controlled by the values of parameters Q1, Q2, and Q3.

Partition of spaces algorithm for solving reactive power problem:

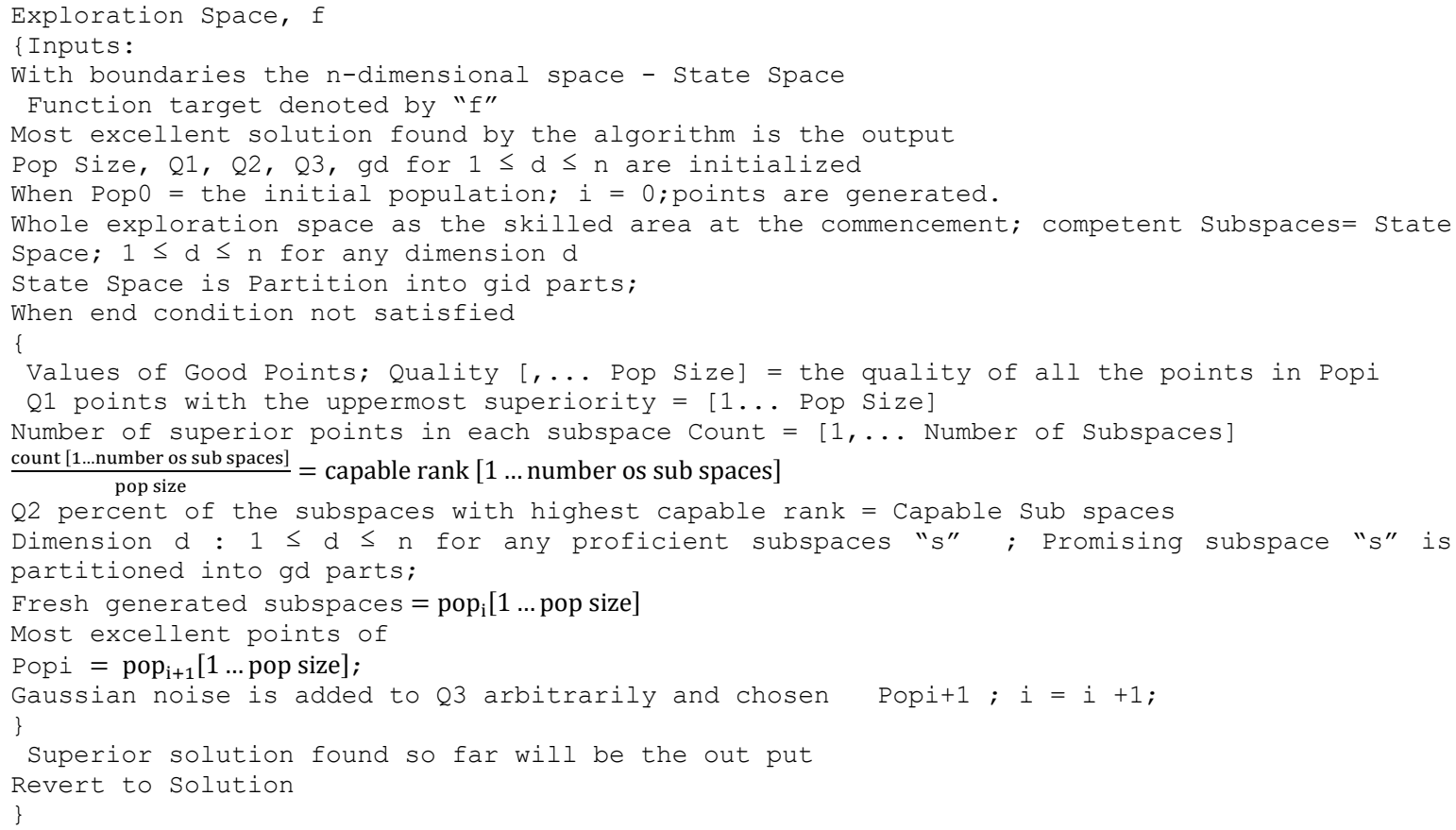

\section{SIMULATION RESULTS}

Performance of partition of spaces algorithm evaluated in standard IEEE 118-bus test system [20]. Limitations on reactive power source are listed in Table 1. Table 2 clearly shows better performance of the proposed algorithm. In IEEE 300 bus system, partition of spaces algorithm is verified [20]. Table 3 shows the values of comparison. Figure 1 gives real power loss comparison for IEEE 118 bus test system and Figure 2 shows the active power loss comparison for IEEE 300 bus test system.

Table 1. Reactive power sources limits

\begin{tabular}{cccccccccccccccc}
\hline BUS NO & 5 & 34 & 37 & 44 & 45 & 46 & 48 & 74 & 79 & 82 & 83 & 105 & 107 & 110 \\
\hline QC & 0.00 & 14.0 & 0.00 & 10.0 & 10.0 & 10.0 & 15.0 & 12.00 & 20.0 & 20.0 & 10.0 & 20.0 & 6.00 & 6.00 \\
MAX & & & & & & & & & & 0.00 & 0.00 & 0.00 & 0.00 & 0.00 & 0.00 \\
QC & -40. & 0.00 & -25. & 0.00 & 0.00 & 0.00 & 0.00 & 0.00 & 0.00 & 0.00 \\
MIN & & & & & & & & & & & & &
\end{tabular}

Table 2. Real power loss comparison results

\begin{tabular}{ccccc}
\hline $\begin{array}{c}\text { Active power loss } \\
\text { (p.u) }\end{array}$ & $\begin{array}{c}\text { Method- BBO } \\
{[21]}\end{array}$ & $\begin{array}{c}\text { Method- ILSBBO/strategy1 } \\
{[21]}\end{array}$ & $\begin{array}{c}\text { Method -ILSBBO/Strategy2 } \\
{[21]}\end{array}$ & $\begin{array}{c}\text { Projected algorithm - } \\
\text { Partition of spaces algorithm }\end{array}$ \\
\hline Minimum & 128.770 & 126.980 & 124.780 & 116.640 \\
Maximum & 132.640 & 137.340 & 132.390 & 120.980 \\
Average value & 130.210 & 130.370 & 129.220 & 117.560 \\
\hline
\end{tabular}

Table 3 Comparison of loss

\begin{tabular}{ccccc}
\hline Parameter & $\begin{array}{c}\text { Method CSA } \\
{[22]}\end{array}$ & $\begin{array}{c}\text { Method EGA } \\
{[23]}\end{array}$ & $\begin{array}{c}\text { Method EEA } \\
{[23]}\end{array}$ & $\begin{array}{c}\text { Partition } \\
\text { of spaces }\end{array}$ \\
\hline PLOSS (MW) & 635.8942 & 646.2998 & 650.6027 & 629.5431 \\
\hline
\end{tabular}




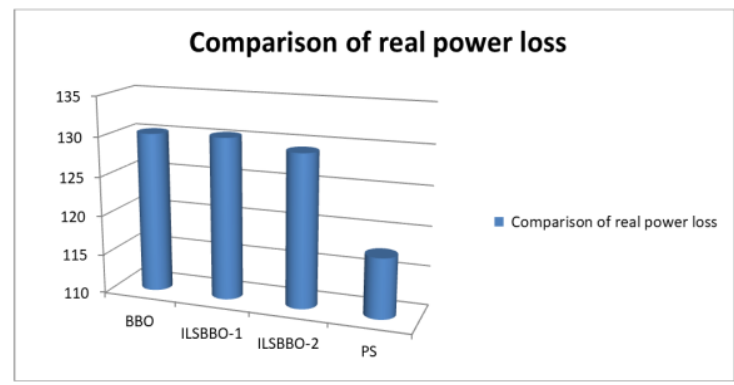

Figure 1. Real power loss comparison

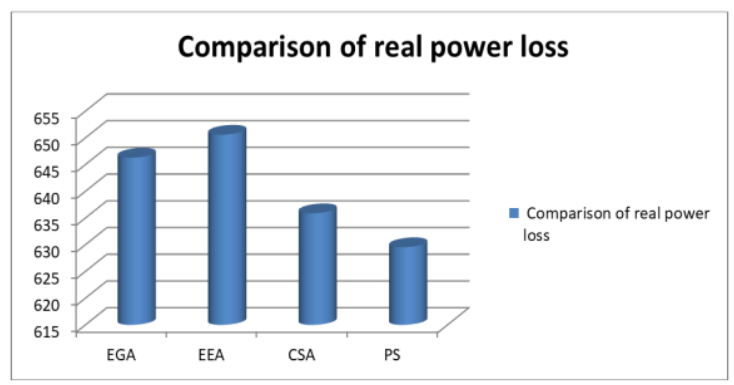

Figure 2. Active power loss comparison

\section{CONCLUSION}

Partition of spaces algorithm has been efficiently applied for solving reactive power problem. In this approach, elevated quality and capable points of the area is taken. State space are identified and divided into subspaces iteratively and search has been made more comprehensively. Efficiency of the proposed algorithm is evaluated in standard IEEE 118,300 bus systems and simulated outcome gives better results when compared to other reported standard algorithms.

\section{REFERENCES}

[1] O. Alsac and B. Stott, "Optimal Load Flow with Steady-State Security," in IEEE Transactions on Power Apparatus and Systems, vol. PAS-93, no. 3, pp. 745-751, May 1974.

[2] K. Y. Lee, Y. M. Park and J. L. Ortiz, "A United Approach to Optimal Real and Reactive Power Dispatch," in IEEE Transactions on Power Apparatus and Systems, vol. PAS-104, no. 5, pp. 1147-1153, May 1985.

[3] A. Monticelli, M. V. F. Pereira and S. Granville, "Security-Constrained Optimal Power Flow with PostContingency Corrective Rescheduling," in IEEE Transactions on Power Systems, vol. 2, no. 1, pp. 175-180, Feb. 1987.

[4] N. Deeb and S. M. Shahidehpour, "Linear reactive power optimization in a large power network using the decomposition approach," in IEEE Transactions on Power Systems, vol. 5, no. 2, pp. 428-438, May 1990.

[5] E. Hcbson, "Network Constrained Reactive Power Control Using Linear Programming," in IEEE Transactions on Power Apparatus and Systems, vol. PAS-99, no. 3, pp. 868-877, May 1980.

[6] K. Y. Lee, Y. M. Park and J. L. Ortiz, "Fuel-cost minimisation for both real-and reactive-power dispatches," in IEE Proceedings C - Generation, Transmission and Distribution, vol. 131, no. 3, pp. 85-93, May 1984.

[7] M. K. Mangoli, K. Y. Lee and Y. M. Park, "Optimal real and reactive power control using linear programming," Electric Power Systems Research, vol. 26, no. 2, pp. 1-10, January 1993.

[8] S. R. Paranjothi and K. Anburaja, "Optimal power flow using refined genetic algorithm," Electr.Power Compon. Syst., vol 30, no. 10, pp. 1055-1063, 2002.

[9] A. Berizzi, C. Bovo, M. Merlo and M. Delfanti, "A GA approach to compare ORPF objective functions including secondary voltage regulation," Electric Power Systems Research, vol. 84, no. 1, pp. 187-194, 2012.

[10] Chien-Feng Yang, G. G. Lai, Chia-Hau Lee, Ching-Tzong Su and G. W. Chang, "Optimal setting of reactive compensation devices with an improved voltage stability index for voltage stability enhancement," International Journal of Electrical Power and Energy Systems, vol. 37, no. 1, pp. 50-57, 2012.

[11] P. K. Roy, S. P.Ghoshal and S. S.Thakurb, "Optimal VAR control for improvements in voltage profiles and for real power loss minimization using Biogeography Based Optimization," International Journal of Electrical Power and Energy Systems, vol. 43, no. 1, pp. 830-838, 2012.

[12] B. Venkatesh, G. Sadasivam and M. A. Khan, "A new optimal reactive power scheduling method for loss minimization and voltage stability margin maximization using successive multi-objective fuzzy LP technique," in IEEE Transactions on Power Systems, vol. 15, no. 2, pp. 844-851, May 2000.

[13] Wei Yan, Shuai Lu and D. C. Yu, "A novel optimal reactive power dispatch method based on an improved hybrid evolutionary programming technique," in IEEE Transactions on Power Systems, vol. 19, no. 2, pp. 913-918, 2004.

[14] Wei Yan, Fang Liu, C. Y. Chung and K. P. Wong, "A hybrid genetic algorithm-interior point method for optimal reactive power flow," in IEEE Transactions on Power Systems, vol. 21, no. 3, pp. 1163-1169, Aug. 2006.

[15] J. Yu, W. Yan, W. Li, C. Y. Chung and K. P. Wong, "An Unfixed Piecewise-Optimal Reactive Power-Flow Model and its Algorithm for AC-DC Systems," in IEEE Transactions on Power Systems, vol. 23, no. 1, pp. 170-176, 2008.

[16] F. Capitanescu, "Assessing Reactive Power Reserves With Respect to Operating Constraints and Voltage Stability," in IEEE Transactions on Power Systems, vol. 26, no. 4, pp. 2224-2234, Nov. 2011.

[17] Zechun Hu, Xifan Wang and Gareth Taylor, "Stochastic optimal reactive power dispatch: Formulation and solution method," International Journal of Electrical Power and Energy Systems, vol. 32, no. 6, pp. 615-621, 2010. 
[18] Janli Zhou, Brian G. Tang and Xing W. Ren, "Research on prediction model for icing thickness of transmission lines based on bp neural network optimized with improved fruit fly algorithm," AMSE Journals-AMSE IIETA Publication Series: Advances, vol. 60, no. 1, pp. 255-269, 2017.

[19] M. Kaedi, "Fractal-based Algorithm: A New Metaheuristic Method for Continuous Optimization," International Journal of Artificial Intelligence, vol. 15, no. 1, pp. 76-92, 2017.

[20] IEEE, "The IEEE 30-bus test system and the IEEE 118-test system," 1993, http://www.ee.washington.edu/trsearch/pstca/.

[21] Jiangtao Cao, Fuli Wang and Ping Li, "An Improved Biogeography-based Optimization Algorithm for Optimal Reactive Power Flow," International Journal of Control and Automation, vol.7, no. 3, pp.161-176, 2014.

[22] S. Surender Reddy," Optimal Reactive Power Scheduling Using Cuckoo Search Algorithm," International Journal of Electrical and Computer Engineering, vol. 7, no. 5, pp. 2349-2356. 2017.

[23] S. Surender Reddy and P. R. Bijwe, A. R. Abhyankar, "Faster evolutionary algorithm based optimal power flow using incremental variables," International Journal of Electrical Power \& Energy Systems, vol. 54, pp. 198-210, 2014.

\section{BIOGRAPHY OF AUTHOR}

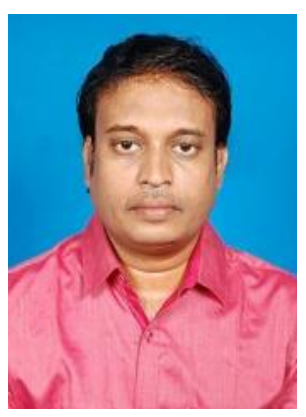

Kanagasabai Lenin has received his B.E., degree, electrical and electronics engineering from University of Madras, M.E., degree in power systems from Annamalai University and completed PhD in electrical engineering from Jawaharlal Nehru Technological University Hyderabad, India. He published more than 275 international journal research papers and presently working as Professor in Prasad V. Potluri Siddhartha Institute of Technology, Kanuru, Vijayawada, Andhra Pradesh -520007. 